American Journal of Applied Sciences 8 (2): 129-133, 2011

ISSN 1546-9239

(C) 2010 Science Publications

\title{
Reduction of Over Line Current in Power System from Short Circuit Effect Using Static Synchronous Series Compensator
}

\author{
Prechanon Kumkratug \\ Department of Electrical Engineering, Faculty of Engineering at Si Racha, \\ Kasetsart University, 199 M.6, Tungsukhla, Si Racha, Chonburi, 20230, Thailand
}

\begin{abstract}
Problem statement: One of the major problems in power system is the over line current from short circuit effect. It may cause in the electrical apparatus outages. Approach: Static Synchronous Series Compensator (SSSC) is a power electronic based device that has the capability of controlling the line current. This study applies the SSSC to decrease the over line current in power system during dynamic state. To verify the effect of the SSSC on over line current reduction, the mathematical model of power system equipped with a SSSC is presented. The variation curve of line current of the faulted system with without and with a SSSC is tested and compared in various cases. Results: The line current of the system without a SSSC is continuously oscillation and the maximum value is much more than the system with a SSSC. Conclusion: SSSC can decrease over line current in power system from short circuit effect.
\end{abstract}

Key words: Over line current, power system stability, FACTS devices, static synchronous, Static Synchronous Series Compensator (SSSC), Single Machine Infinite Bus (SMIB), transformer leakage, voltage injection, voltage source, short circuit, High Voltage Direct Current (HVDC), Flexible AC Transmission System (FACTS)

\section{INTRODUCTION}

The short circuit in power system is unavoidable situation and it provides the high current. It may cause in power apparatus outage. One of the major problems in power system is the over line current from short circuit effect (Barbuy et al., 2009; Coe and Laosethakul, 2010; Subramanian et al., 2010; Barnes et al., 2009). They have proposed many methods to improve stability of power system such as load shedding, High Voltage Direct Current (HVDC), Flexible AC Transmission System (FACTS), (Matondang and Jambak, 2010; El-Shennawy et al., 2010; Hannan et al., 2009; Magaji and Mutafa, 2009; Wong and Lee, 2009; Metkar and Talbar, 2010; Mustafa and Magaji, 2009).

A Static Synchronous Series Compensator (SSSC) is a member of the FACTS family that is connected in series with power system. The SSSC consists of a solid state voltage source converter with GTO thyristor switches or other high performance of semi-conductor and transformer. The SSSC can electrically mimic reactor and capacitor by injecting a shunt current in quadrature with the line voltage. The reactive power (or current) of the SSSC can be adjusted by controlling the magnitude and phase angle of the output voltage of the shunt converter (Ahmad and Al-Husban, 2009; Bagher at el., 2009; Hashim and Marghany, 2009; Zahim et al., 2009).
This study presents the method of decreasing over line current in power system from short circuit effect by using a SSSC. The mathematical model of power system equipped with a SSSC is systematically derived. The simulation results are tested on a Single Machine Infinite bus system. The effect of SSSC on reduction of over line current is investigated in various cases.

\section{MATERIALS AND METHODS}

Mathematical Model: Figure 1a shows the single line diagram of Single Machine Infinite Bus (SMIB) system without a SSSC and the corresponding equivalent circuit is shown in Fig. 1b. Here $\mathrm{X}_{1}$ is the equivalent reactance between the machine internal bus and the bus $\mathrm{m}$ and $\mathrm{X}_{2}$ is the equivalent reactance between bus $\mathrm{m}$ and the infinite bus. The generator is represented by a constant voltage source (E') behind transient reactance $\left(\mathrm{X}_{\mathrm{d}}^{\prime}\right)$.

Consider the system without a $\mathrm{SSSC}$ as shown in Fig. 1, the line current is given by:

$$
\begin{aligned}
\mathbf{I}_{0} & =\frac{\mathbf{E}^{\prime}-\mathrm{V}_{\mathrm{b}}}{j \mathrm{X}} \\
& =\frac{\left(\mathrm{E}^{\prime} \cos \delta+j \mathrm{E}^{\prime} \sin \delta\right)-\left(\mathrm{V}_{\mathrm{b}}\right)}{j \mathrm{X}} \\
& =\left(\frac{E^{\prime}}{\mathrm{X}} \sin \delta\right)+j\left(-\frac{E^{\prime}}{X} \cos \delta+\frac{V_{b}}{X}\right)
\end{aligned}
$$




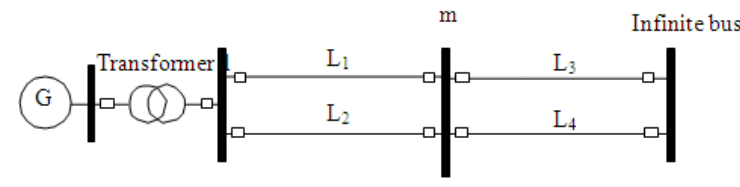

(a)

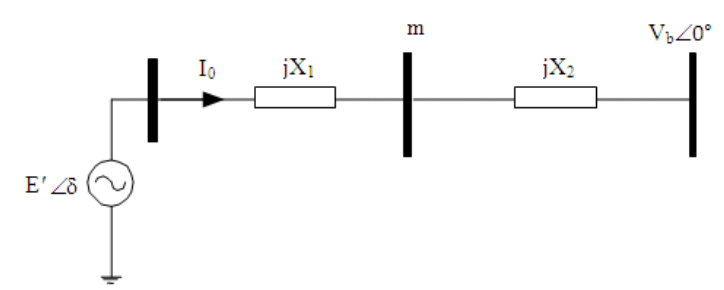

(b)

Fig. 1: Single machine infinite bus system schematic diagram (b) equivalent circuit

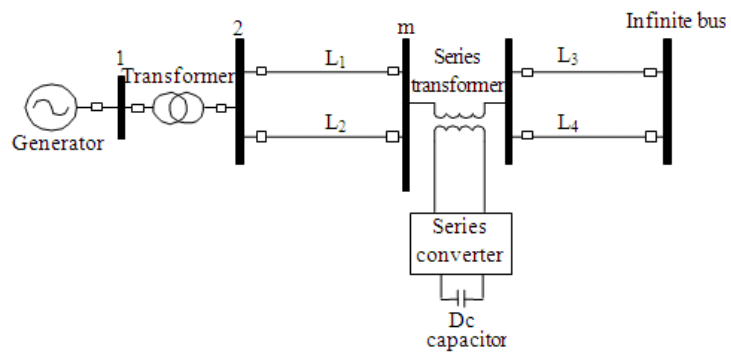

(a)

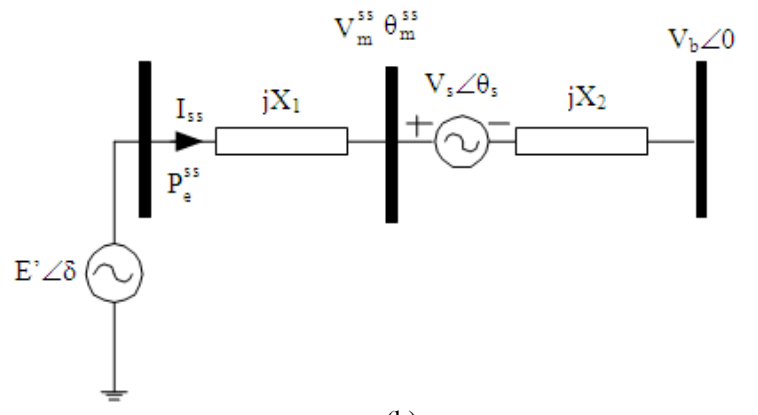

(b)

Fig. 2: Single machine infinite bus system with a SSSC (a) schematic diagram (b) equivalent circuit of system with a SSSC represented by a series voltage injection

Here $\mathrm{X}=\mathrm{X}_{1}+\mathrm{X}_{2}$ :

$\theta=\tan ^{-1}\left[\frac{\mathrm{V}_{\mathrm{b}}-\mathrm{E}^{\prime} \cos \delta}{\mathrm{E}^{\prime} \sin \delta}\right]$

The output electrical power of the system without a $\mathrm{SSSC}$ is given by:

$\mathrm{P}_{\mathrm{e}}^{0}=\frac{\mathrm{E}^{\prime} \mathrm{V}_{\mathrm{b}}}{\mathrm{X}} \sin \delta$

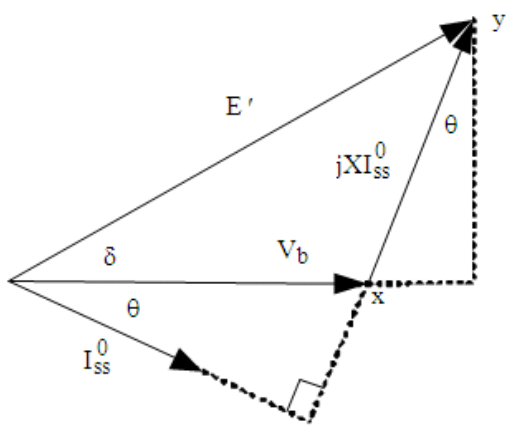

(a)

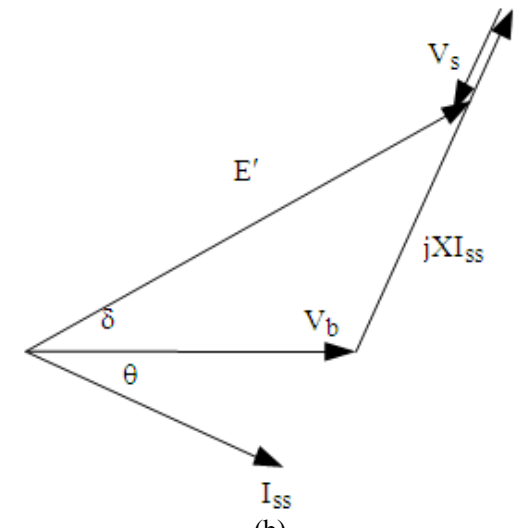

(b)

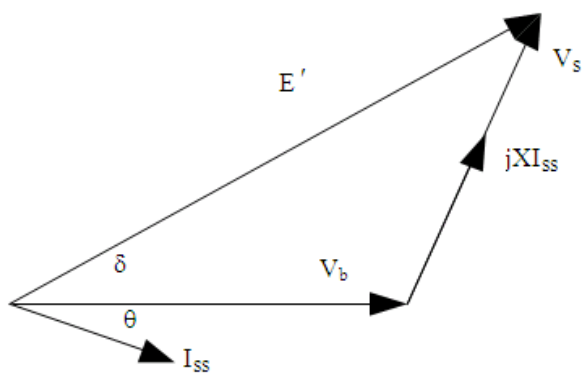

(c)

Fig. 3: Phasor diagram (a) without a SSSC (b) with a SSSC operating in capacitive mode (c) with a SSSC operating in reactive mode

Now, consider the system with a SSSC as shown in Fig. 2. The Fig. $2 b$ represents the equivalent circuit of Fig. 2a. The SSSC is represented by a series voltage injection $\left(\mathrm{V}_{\mathrm{s}}\right)$ and transformer leakage reactance. When $\mathrm{V}_{\mathrm{S}}$ is positive, the SSSC supplies the reactive power to the system, it is called capacitive mode and then the series voltage angle $\theta_{\mathrm{s}}$ is in lagging with the line current as shown in Fig. $3 \mathrm{~b}$ whereas $\mathrm{V}_{\mathrm{s}}$ is negative, the SSSC absorbs the reactive power to the system, it is called reactive mode and then the series voltage angle $\theta_{\mathrm{s}}$ is in leading with the line current as shown in Fig. 3c. 
From Fig. 2b, the line current of the system with a SSSC is given by:

$$
\begin{aligned}
\mathbf{I}_{\mathrm{ss}} & =\frac{\mathbf{E}^{\prime}-\mathbf{V}_{\mathrm{s}}-\mathrm{V}_{\mathrm{b}}}{\mathrm{jX}} \\
& =\left[\frac{\mathbf{E}^{\prime}-\mathrm{V}_{\mathrm{b}}}{\mathrm{jX}}\right]+\left[\frac{-\mathbf{V}_{\mathrm{s}}}{\mathrm{jX}}\right]
\end{aligned}
$$

From the Eq. 1 and 4, the line current of the system with a SSSC is given by:

$$
\mathbf{I}_{\mathrm{ss}}=\mathbf{I}_{0}+\Delta \mathbf{I}
$$

Here, $\Delta \mathbf{I}=\frac{-\mathbf{V}_{\mathrm{s}}}{\mathrm{jX}}$

From Eq. 1 and $4, \Delta \mathrm{I}$ is the additional component of the system of a SSSC.

From the phasor diagram as shown in Fig. 3, it indicates that the SSSC doesn't change the line current angle. However, the SSSC affects on the line current magnitude. When $\mathrm{V}_{\mathrm{s}}$ lags line current 90 degree, the line current magnitude is increased and when $\mathrm{V}_{\mathrm{s}}$ leads line current 90 degree, the line current magnitude is decreased as can be seen in Fig. 3.

\section{MATERIALS AND METHODS}

The dynamic of power system as shown in Fig. 2a can be expressed by following equations

$\dot{\delta}=\omega$

$\dot{\omega}=\frac{1}{\mathrm{M}}\left[\mathrm{P}_{\mathrm{m}}-\mathrm{P}_{\mathrm{e}}^{\mathrm{ss}}\right]$

Here, $\delta, \omega, \mathrm{P}_{\mathrm{m}}, \mathrm{M}$ and $\mathrm{P}_{\mathrm{e}}^{\mathrm{ss}}$ are the rotor angle, speed deviation, mechanical input power, moment of inertia and electrical output power. The output electrical power equation of generator can be expressed by:

$$
\begin{aligned}
\mathrm{P}_{\mathrm{e}}^{\mathrm{ss}} & =\operatorname{Re}\left[\mathbf{E}^{\prime}\left(\mathbf{I}_{\mathrm{ss}}\right)^{*}\right] \\
& =\operatorname{Re}\left[\mathbf{E}^{\prime}\left(\mathbf{I}_{\mathbf{0}}\right)^{*}\right]+\operatorname{Re}\left[\mathbf{E}^{\prime}(\Delta \mathbf{I})^{*}\right]
\end{aligned}
$$

The first term of Eq. 8 represents the system without a SSSC. The second term is the additional component from the $\operatorname{SSSC}\left(\Delta \mathrm{P}_{\mathrm{e}}^{\mathrm{ss}}\right)$ rewritten by:

$$
\mathrm{P}_{\mathrm{e}}^{\mathrm{ss}}=\mathrm{P}_{\mathrm{e}}+\Delta \mathrm{P}_{\mathrm{e}}^{\mathrm{ss}}
$$

The $\Delta \mathrm{P}_{\mathrm{e}}^{\mathrm{ss}}$ is written by:

$$
\begin{aligned}
\Delta \mathrm{P}_{\mathrm{e}}^{\mathrm{ss}} & =\operatorname{Re}\left[\mathbf{E}^{\prime}\left(\frac{-\mathbf{V}_{\mathrm{s}}}{\mathrm{j} \mathrm{X}_{2}}\right)^{*}\right] \\
& =\operatorname{Re}\left[\mathrm{E}^{\prime} \angle \delta\left(\frac{-\mathrm{V}_{\mathrm{s}} \angle \theta_{\mathrm{s}}}{\mathrm{jX}}\right)^{*}\right] \\
& =\frac{\mathrm{E}^{\prime} \mathrm{V}_{\mathrm{s}}}{\mathrm{X}} \sin \left(\delta-\theta_{\mathrm{s}}\right)
\end{aligned}
$$

Here:

$$
\Delta \mathrm{P}_{\mathrm{e}}^{\mathrm{ss}}=\frac{\mathrm{E}^{\prime} \mathrm{V}_{\mathrm{s}}}{\mathrm{X}} \cos (\delta-\theta)
$$

From the Eq. 2, it can be written by:

$\mathrm{E}^{\prime} \sin \delta \sin \theta=\mathrm{V}_{\mathrm{b}} \cos \theta-\mathrm{E}^{\prime} \cos \delta \cos \theta$

With some mathematical manipulations of Eq. 11, it can be written by:

$\cos (\delta-\theta)=\frac{V_{\mathrm{b}}}{\mathrm{E}^{\prime}} \cos (\theta)$

From the Fig. 3, the cosine of the line current angle is given by:

$$
\begin{aligned}
\cos (\theta) & =\frac{\mathrm{E}^{\prime} \sin (\delta)}{\mathrm{xy}} \\
& =\frac{\mathrm{E}^{\prime} \sin (\delta)}{\sqrt{\left(\mathrm{E}^{\prime}\right)^{2}+\left(\mathrm{V}_{\mathrm{b}}\right)^{2}-2 \mathrm{E}^{\prime} \mathrm{V}_{\mathrm{b}} \cos (\delta)}}
\end{aligned}
$$

From Eq. 10 and 13, the additional component of output electrical power is:

$\Delta \mathrm{P}_{\mathrm{e}}^{\mathrm{ss}}=\frac{\mathrm{V}_{\mathrm{s}} \mathrm{E}^{\prime} \mathrm{V}_{\mathrm{b}}}{\mathrm{X} \sqrt{\left(\mathrm{E}^{\prime}\right)^{2}+\left(\mathrm{V}_{\mathrm{b}}\right)^{2}-2 \mathrm{E}^{\prime} \mathrm{V}_{\mathrm{b}} \cos \delta}} \sin \delta$

From Eq. 8 and 14, the output electrical power of system with a SSSC is given by:

$$
\mathrm{P}_{\mathrm{e}}^{\mathrm{ss}}=\mathrm{P}_{\mathrm{e}}+\frac{\mathrm{V}_{\mathrm{s}} \mathrm{P}_{\mathrm{e}}}{\sqrt{\left(\mathrm{E}^{\prime}\right)^{2}+\left(\mathrm{V}_{\mathrm{b}}\right)^{2}-2 \mathrm{E}^{\prime} \mathrm{V}_{\mathrm{b}} \cos \delta}}
$$

It can be seen from Eq. 15 that the output electrical power flow can be controlled by a SSSC. With positive value of $V_{s}$, the output electrical power is increased whereas with negative value of $\mathrm{V}_{\mathrm{s}}$, the output electrical power is reduced. Thus the control strategy of SSSC is given by:

$$
\mathrm{V}_{\mathrm{s}}=\mathrm{k} \omega
$$

Here, $\mathrm{k}$ is constant gain control. 


\section{RESULTS}

The proposed model of decreasing over line current in faulted power system equipped with a SSSC is investigated on sample system. Fig. 4 shows the sample system. The system parameters are:

$\mathrm{M}=5.6, \mathrm{X}_{\mathrm{t}}=0.1, \mathrm{X}_{\mathrm{d}}^{\prime}=3, \mathrm{X}_{\mathrm{L} 1}=0.4, \mathrm{X}_{\mathrm{L} 2}=0.4, \mathrm{X}_{\mathrm{L} 3}=0.9$, $\mathrm{X}_{\mathrm{L} 4}=0.4, \mathrm{P}_{\mathrm{m}}=0.9$

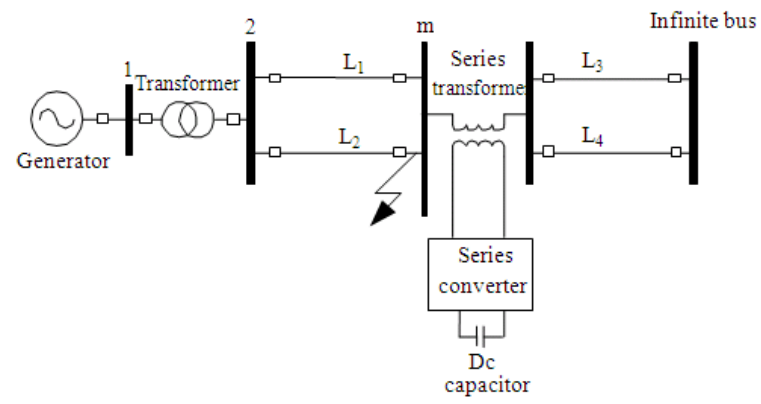

Fig. 4: Sample system

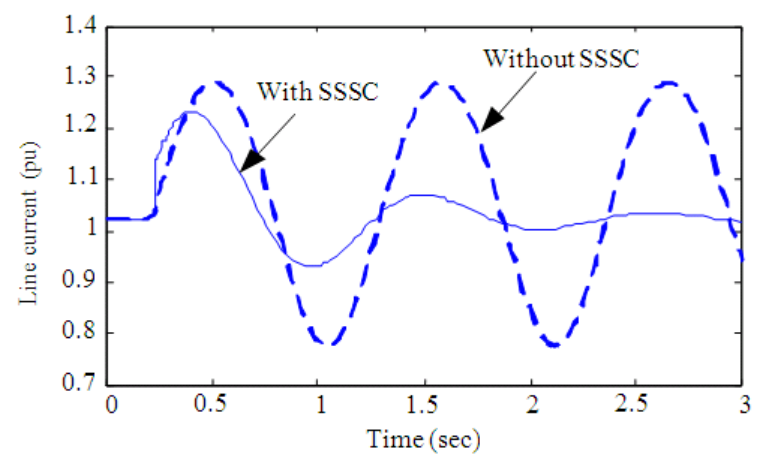

Fig. 5: Line current of the faulted system with $t_{\mathrm{cl}}=$ $130 \mathrm{msec}$

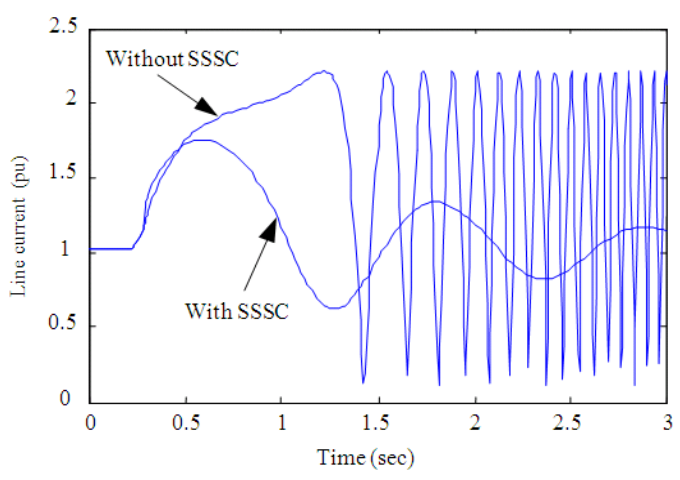

Fig. 6: Line current of the faulted system with $t_{c l}=140$ msec
It is considered that a 3-phase fault appears on line $\mathrm{L} 1$ and it is cleared by opening the faulted line. Figure 5 shows the variation curve of line current of the system with clearing fault time $\left(t_{\mathrm{cl}}\right) 130 \mathrm{msec}$ and Fig. 6 shows the variation curve of line current of the system with clearing fault time $\left(\mathrm{t}_{\mathrm{cl}}\right) 138 \mathrm{msec}$.

\section{DISCUSSION}

It can be observed from the simulation results that with $\mathrm{t}_{\mathrm{cl}}=130 \mathrm{msec}$ and without a SSSC $(\mathrm{K}=0)$, the line current continuously oscillation and with a SSSC, the line current can return to normal steady state at few seconds. With increasing $t_{\mathrm{cl}}$ to $138 \mathrm{msec}$, the over line current of the system without a SSSC is increased much more and higher frequency. However, the over line current can be significant reduced by using the SSSC.

\section{CONCLUSION}

This study presents the method of decreasing over line current in power system from short circuit effect by using a SSSC. The mathematical model of power system equipped with a SSSC is systematically derived. It was found from the proposed model that the line current can be controlled by a SSSC. The simulation results are tested on a Single Machine Infinite bus system. It was found from the simulation results that the SSSC can decrease over line current in power system from short circuit effect.

\section{REFERENCES}

Ahmad and N. Al-Husban, 2009. An eigenstructure assignment for a static synchronous compensator. Am. J. Eng. Applied Sci., 2: 812-816. DOI: 10.3844/ajeassp.2009.812.816

Bagher, M., B. Sharifian, M.R. Feyzi, S.H. Hosseini and R. Valinia, 2009. Implementing a vector controller using $68 \mathrm{k}$ processors. Am. J. Eng. Applied Sci., 2: 488-493. DOI: 10.3844/ajeassp.2009.488.493

Barbuy, H.S., A. Rocco, L.A.P. Fernandes and G.C. Guimaraes, 2009. Voltage collapse risk associated to under-voltage capacitive compensation in electric power system operation. Am. J. Applied Sci., 6: 646-651. 10.3844/ajassp.2009.646.651

Barnes, B., H. Cao, T. Drab and J. Pearson, 2009. Design of Sustainable relief housing in ethiopia: an implementation of cradle to cradle design in earthbag construction. Am. J. Environ. Sci., 5: 137-144. DOI: 10.3844/ajessp.2009.137.144 
Coe, T.S. and K. Laosethakul, 2010. Should individual investors use technical trading rules to attempt to beat the market? Am. J. Econ. Bus. Admin., 2: 201-209. DOI: 10.3844/ajebasp.2010.201.209

El-Shennawy, T.I., A.M. Moussa, M.A. El-Gammal and A.Y. Abou-Ghazala, 2010. A dynamic voltage restorer for voltage sag mitigation in a refinery with induction motors loads. Am. J. Eng. Applied Sci., 3: 144-151. DOI: 10.3844/ajeassp.2010.144.151

Hannan, M.A., A. Mohamed, A. Hussian and M. Dabbay, 2009. Development of the unified seriesshunt compensator for power quality mitigation. Am. J. Applied Sci., 6: 978-986. DOI: 10.3844/ajassp.2009.978.986

Hashim, M. and M. Marghany, 2009. Robust of doppler centroid for mapping sea surface current by using radar satellite data. Am. J. Eng. Applied Sci., 2: 781-788. DOI: 10.3844 /ajeassp.2009.781.788

Magaji, N. and M.W. Mutafa, 2009. Optimal thyristor control series neuro-controller for damping oscillations. J. Comput. Sci., 5: 983-990.

Matondang, M.Z. and M.I. Jambak, 2010. Soft computing in optimizing assembly lines balancing. J. Comput. Sci., 6: 141-162. DOI: 10.3844/jcssp.2010.141.162
Metkar, S.P. and S.N. Talbar, 2010. Motion detection and projection based block motion estimation using the radon transform for video coding. J. Comput. Sci., 6: 979-986. DOI: 10.3844/jcssp.2010.979.986

Mustafa, M.W. and N. Magaji, 2009. Optimal location of static var compensator device for damping oscillations. Am. J. Eng. Applied Sci., 2: 353-359. DOI: 10.3844/ajeassp.2009.353.359

Subramanian, R., S. N. Sivanandam and C. Vimalarani, 2010. An optimization of design for s4-duty induction motor using constraints normalization based violation technique. J. Comput. Sci., 6: 107-111. DOI: $10.3844 /$ jcssp.2010.107.111

Wong, L. and L.S. Lee, 2009. Heuristic placement routines for two-dimensional bin packing problem. J. Math. Stat., 5: 334-341. DOI: 10.3844/jmssp.2009.334.341

Zahim, S.M., M. Norainon, J.M. Shawal and R.I.R.M. Taufika, 2009. Iterative numerical method of gate turn-off thyristor: Comparative study between $\mathrm{Si}$ and $\mathrm{SiC}$. Am. J. Eng. Applied Sci., 2 : $446-450 . \quad$ DOI: 10.3844/ajeassp.2009.446.450 